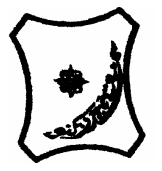

Bayero Journal of Pure and Applied Sciences, 8(2): 210 - 215

Received: October, 2015

Accepted: November, 2015

ISSN $2006-6996$

\title{
CHARACTER ASSOCIATION AND PATH COEFFICIENT ANALYSIS BETWEEN SOME GROWTH CHARACTERS AND GRAIN YIELD IN SOYBEAN ( GLYCINE MAX (L.) MERRIL.)
}

\author{
Yahaya, S. U.* and Ankrumah, E. \\ *Department of Agronomy, Bayero University, Kano, Nigeria. \\ International Institute of Tropical Agriculture, Kano Station, Kano, Nigeria. \\ Corresponding author: suyahya2007@yahoo.com
}

\begin{abstract}
Field experiment was conducted in 2014 rainy season at the Agricultural Research Station Farm, Minjibir (12 $11^{\prime} \mathrm{N}$ and $\left.8^{\circ} 25^{\prime} \mathrm{E}\right)$, and Bayero University, Kano $\left(11^{\circ} 58^{\prime} \mathrm{N}\right.$ and $\left.8^{\circ} 25^{\prime} \mathrm{E}\right)$, Teaching and Research Farm. This work was aimed at studying the nature and magnitude of the associations of some growth characters and grain yield in Soybean, a basis of selection for further improvement. Treatments consisted of two levels of rhizobium inoculation, three $(0,10$, and $20 \mathrm{kgN} / \mathrm{ha}$ ) levels of nitrogen and three $\left(0,30\right.$, and $\left.60 \mathrm{~kg} \mathrm{P}_{2} \mathrm{O}_{5} \mathrm{ha}^{-1}\right)$ levels of phosphorus. These were laid out in split-split plot design with three replications. Results of the study showed that number of branches was positively $(p<0.01)$ correlated to grain yield. The path analysis also revealed that number of branches has the greatest direct effect on the grain yield. The greatest combined contributions of growth characters to grain yield were recorded from number of leaves and number of branches. Based on these findings, attention can be given towards improvement of number of branches per plant and number of leaves as criteria for selection of Soybean for increased grain yield.
\end{abstract}

Keywords: Correlation, Grain yield, Growth, Path coefficient analysis, Soybean

\section{INTRODUCTION:}

Soybean (Glycine max (L) Merril) is an important grain legume in terms of total production and international trade (Simmond et al., 1999). The crop contains 40 percent high quality protein, 20 percent edible oil, and a good balance of amino acids, carbohydrates, and ash (IITA, 1993). Soybean therefore, has tremendous potential to improve the nutritional status and welfare of resource-poor people particularly in a developing country like Nigeria.

Correlation study was initiated with the prime objective of observing the mutual relationship of different characters and also type and extent of their contribution to yield. Several workers have attempted to determine the linkage between the characters on which the selections for high yields can be made. Khan et al. (2000) reported that the heritability value ranged from $29.371 \%$ for seeds pod-1 to $98.91 \%$ maturity. Similarly, seed yield was positive and significantly correlated with all character except pod height.

Yield is a complex quantitative trait, conditioned by the interaction of various growth and physiological processes (Adeniji and Peter, 2005). Appropriate knowledge of the interrelationships between the grain yield and its contributing growth components can improve the efficiency and use of appropriate selection indices in breeding for higher yield. Hence, direct selection for yield may not be the most efficient method for improvement (Sreenivas et al., 2015). Correlation and path coefficient analysis are thus pre-requisites for improvement of any crop. This is also a simple measure of the association between growth and other traits whose information can be enhanced by partitioning into direct and indirect effects, which also provides a realistic basis for the allocation of appropriate weight to various growth components and yield.

This study is therefore aimed at gathering useful information on growth character associations and path coefficient analysis for use as a criterion for selection in the improvement of grain yield in Soybean. MATERIALS AND METHODS

Field trials were conducted in 2014 rainy season at the Agricultural Research Station, Farm Minjibir $\left(12^{\circ} 11^{\prime} \mathrm{N}\right.$ and $\left.8^{0} 25^{\prime} \mathrm{E}\right)$ and Bayero University, Kano $\left(11^{0} 58^{\prime} \mathrm{N}\right.$ and $\left.8^{0} 25^{\prime} \mathrm{E}\right)$ Teaching and Research Farm, to study the relationships between grain yield and some growth characters in Soybean. The treatments consisted of two (Un-inoculated and inoculated) levels of rhizobium, three $(0,10$, and $20 \mathrm{~kg}$ $\left.\mathrm{ha}^{-1}\right)$ levels of nitrogen, and three $(0,30$, and $60 \mathrm{~kg} \mathrm{ha}$ $\left.{ }^{1}\right)$ levels of phosphorus. Split - split plot design was used with three replications. TGX $1835-10 \mathrm{E}$ soybean variety was used for the purpose of this trial. Each plot consisted of 4 rows of 3 metres long, while the net plot was $4.5 \mathrm{~m}^{2}(1.5 \times 3 \mathrm{~m})$. Legume inoculant (Bradyrhizobium japonicum) in a ratio of $10 \mathrm{~g}$ per $\mathrm{kg}$ soybean were mixed using slurry sticker. Four seeds per hole were planted on ridges of $0.75 \mathrm{~m} \times 0.1 \mathrm{~m}$ spacing. The Un-inoculated seeds were initially sown. This was followed by sowing the inoculated seeds immediately with a view to maintain the potency of the inoculant. 
Nitrogen and phosphate fertilizers from urea $(46 \% \mathrm{~N})$ and single super phosphate $\left(\mathrm{P}_{2} \mathrm{O}_{5}\right) \mathrm{kg} \mathrm{ha}^{-1}$ were basally applied to the designated plots at 7 days after planting as per the treatments. Weeds were controlled manually using hoe at 2, 4 and 6 weeks after planting. There were no pests incidence observed throughout the trial period, hence no pest control measure were taken. Data were collected on plant height, number of leaves per plant, number of branches per plant, leaf area index, plant dry matter and the grain yield. Simple correlation coefficients between the grain yield (y) and the growth characters (x) and within the growth characters themselves were worked out using the following equation after Poohlman (1959).

$$
\text { SPXY }
$$

where $r=$ Correlation coefficient, $S P x y=$ Sum of products of $x$ and $y$

$s S X=$ sum of products of $\mathrm{x}$, i.e., $\Sigma(\mathrm{x}-\ddot{\mathrm{x}})^{2} \quad$ ssy $=$ sum of products of $y$, i.e., $\Sigma(y-\bar{y})^{2}$

The calculated coefficients were further used to develop the following simultaneous equations in order to partition the correlations into cause and effect by working out the path coefficients (PI)

$r_{16}=p_{1}+p_{2} r_{12}+p_{3} r_{13}+p_{4} p_{14}+p_{5} r_{15}$

(1)

$r_{26}=p_{1} r_{12}+p_{2}+p_{3} r_{23}+p_{4} r_{24}+p_{5} r_{25}$

$r_{36}=p_{1} r_{13}+p_{2} r_{23}+p_{3}+p_{4} r_{34}+p_{5} r_{35}$

(3)

$r_{46}=p_{1} r_{14}+p_{2} r_{24}+p_{3} r_{34}+p_{4}+p_{5} r_{45}$

$r_{56}=p_{1} r_{15}+p_{2} r_{25}+p_{3} r_{35}+p_{4} r_{45}+p_{5} \ldots$

From the above equations $p_{1}, p_{2}, p_{3}, p_{4}$ and $p_{5}$ are the path coefficients (direct effects) while $p_{1} r_{13}, p_{1} r_{23}, p_{1} r_{34}$, $p_{1} r_{45}, p_{2} r_{23}, p_{2} r_{24}, p_{2} r_{25}, p_{3} r_{25}, p_{3} r_{34}, p_{3} r_{35}$ and $p_{4} r_{45}$ are the indirect effects while $r_{12} \ldots . . r_{56}$ are the correlation coefficients. The individual and combined percentage contributions of any two characters were also computed using the following relation as described by Gomez and Gomez (1984).

where $\mathrm{E}=$ Percent individual contribution

$E_{i j}=$ Combined percent contribution of characters $i$ and j

$R_{i j}=$ Coefficient of correlation between $i$ and $j$

$P_{i}$ and $p_{j}=$ Path coefficients of characters $i$ and $j$, respectively.

The residual factor $\left(R_{x}\right)$, which represents the unaccounted error by the direct and combined effects, is calculated by the following: while the sum of the percent contribution (individual and combined) as well as the residual should add up to 100.

\section{RESULTS AND DISCUSSION}

The matrix of simple correlation coefficients $(\gamma)$ between grain yield and some growth characters in Soybean is presented in Table 1 . Results of the correlation analysis revealed significant $(p<0.01)$ and positive associations between most of the growth characters to grain yield of Soybean. This indicated that number of branches per plant was significantly ( $p<0.01$ ) and positively correlated to grain yield. There were also significant correlations among the growth characters themselves in which plant height was significantly $(p<0.01)$ correlated to number of leaves, number of branches and the leaf area index, respectively. These indicated the dependency of these characters as more branches bears more leaves with more surface areas and increased photosynthetic capacity to translate to increased grain yield. Similar findings were earlier reported by several authors, some of whom are (Singh et al., 2000; Singh and Yadava., 2000), for improved grain yield in Soybean.

A study of the direct and indirect effect as well as total contributions of some growth characters to grain yield of soybean is presented in Table 2 . This showed that the total contribution of the plant height to yield was 0.368 . Out of this, the direct contribution of plant height was 0.1166 . Similarly, the indirect contribution of plant height via leaf area index and plant dry matter was found to be negative $(-0.1153$ and -0.0053), respectively thus signifying an ill contributions in this association. This also corroborated with the findings of Shahid Iqbal et al. (2003) who reported that improvement of one character could result in partial decrease of the other character. The indirect associations via number of leaves and branches were 0.0947 and 0.2774 , respectively. Results of the study also showed that 0.491 was the total contribution of number of leaves to grain yield. Out of this 0.1964 was directly contributed by the number of leaves. Similarly, 0.0562, 0.3465, -0.1069 and -0.0011 were contributed indirectly via plant height, number of branches, leaf area index and plant dry matter, respectively. The significant and positive contribution of number of leaves to grain 
Table 1: Matrix of correlation coefficient $(\gamma)$ showing association between grain yield and some growth characters of Soybean.

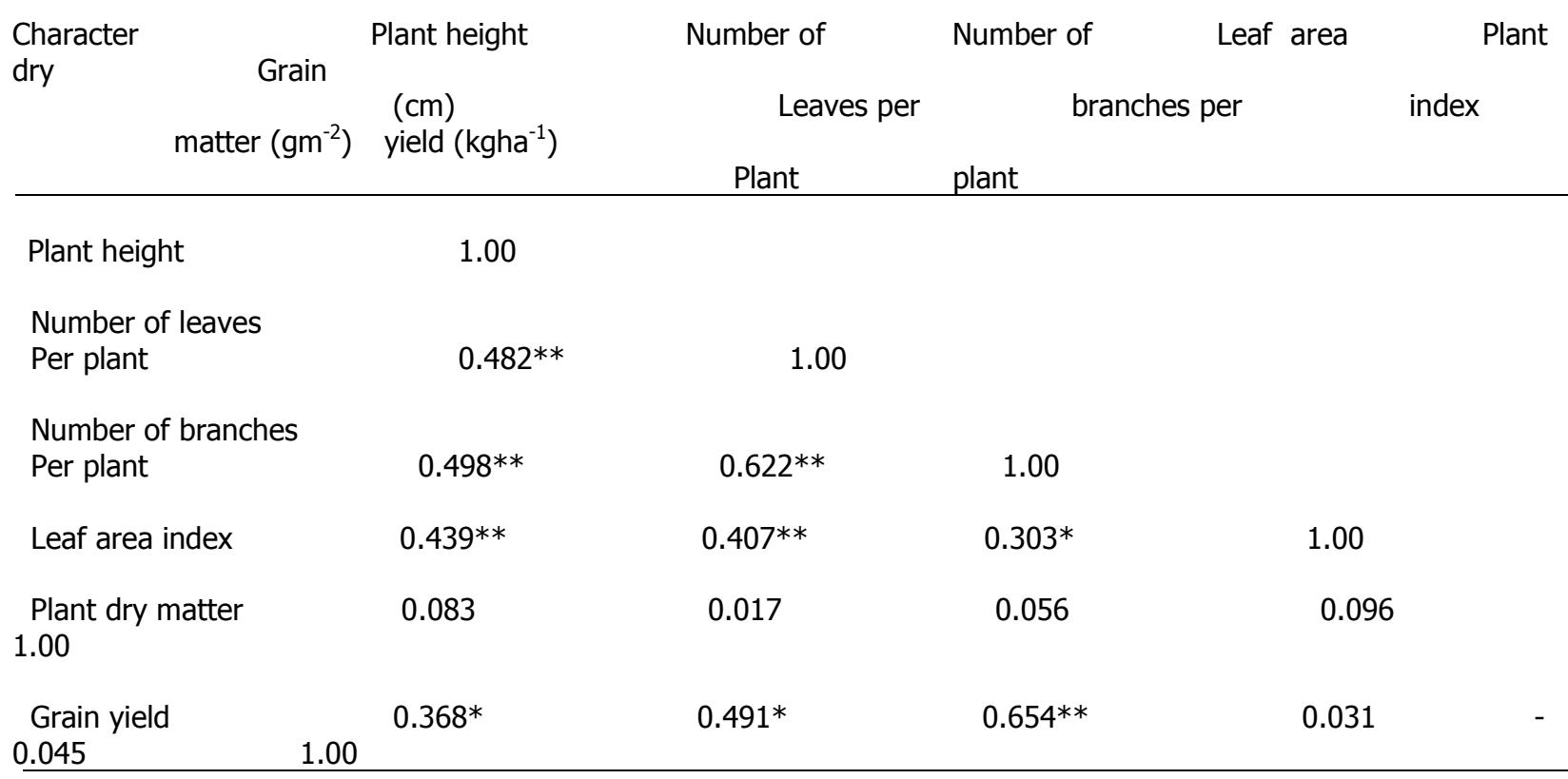

Table 2: Direct, Indirect and Total Contribution of Some Growth Characters to Grain Yield of Soybean.

\begin{tabular}{|c|c|c|c|c|}
\hline \multicolumn{3}{|c|}{ Growth Character } & \multicolumn{2}{|c|}{ Effect Through } \\
\hline & \multirow[t]{2}{*}{$\mathrm{PH}$} & NLVS & \multirow{2}{*}{$\begin{array}{l}\text { NBR } \\
(\mathrm{cm})\end{array}$} & \multirow[t]{2}{*}{ LAI } \\
\hline & & Total Corr. & & \\
\hline \multirow[t]{2}{*}{$\mathrm{PH}$} & $\underline{0.1166}$ & 0.0947 & 0.2774 & -0.1153 \\
\hline & $-0 . \overline{0053}$ & $0.3681 *$ & & \\
\hline \multirow[t]{2}{*}{ NLVS } & 0.0562 & $\underline{0.1964}$ & 0.3465 & -0.1069 \\
\hline & -0.0011 & $0.4911^{*}$ & & \\
\hline \multirow[t]{2}{*}{ NBR } & 0.0581 & 0.1222 & $\underline{0.5570}$ & 0.0796 \\
\hline & -0.0061 & $0.6541^{* *}$ & & \\
\hline \multirow[t]{2}{*}{ LAI } & 0.0512 & 0.0799 & 0.1688 & $\underline{-0.2627}$ \\
\hline & -0.0061 & 0.0311 & & \\
\hline PDM & 0.0097 & 0.0033 & 0.0312 & -0.0252 \\
\hline-0.0640 & -0.0450 & & & \\
\hline
\end{tabular}

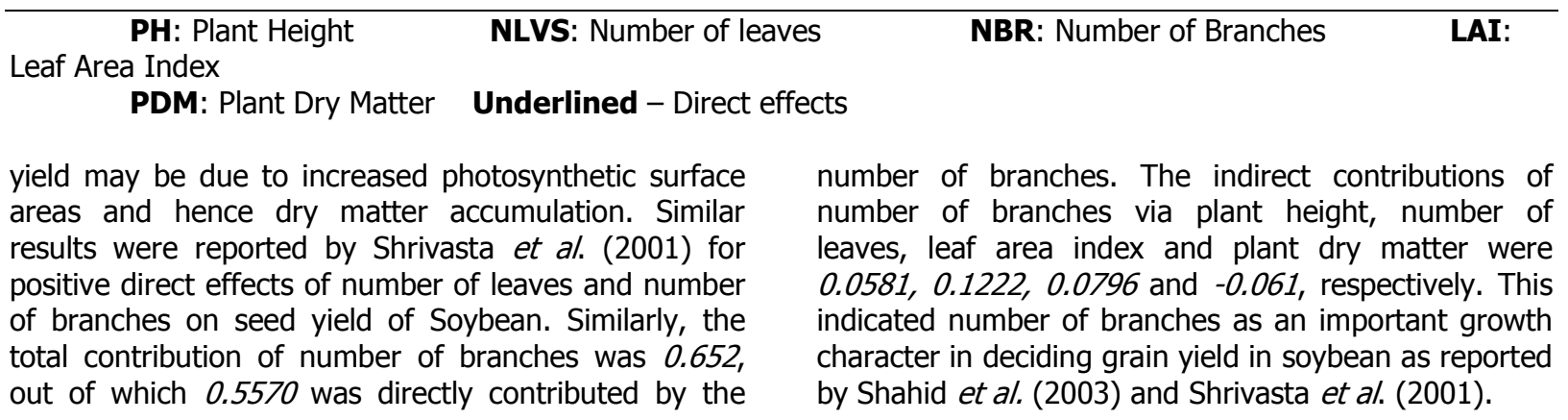


The total contribution of leaf area index was small and insignificant in this study (0.031). Out of this, -0.2627 was directly contributed by the leaf area index. However, only 0.0512, 0.0799, 0.1688 and 0.0061 were contributed indirectly via plant height, number of leaves, number of branches and plant dry matter, respectively. The results also indicated a negative total contribution of plant dry weight $(-0.045)$, out of which only -0.0640 was directly contributed by the plant dry matter. Similarly, the indirect contributions via plant height, number of leaves, number of branches, and leaf area index were 0.0097 , $0.0033,0.0312$ and -0.0252 , respectively.
When the individual percentage contributions of the growth components were examined, it was noted that the percentage (direct) contribution of the plant height was 1.3604 (Table 3). Similarly, the individual percentage (direct) contributions of the number of leaves, number of branches, leaf area index and plant dry matter were 3.8563, 31.0211, 6.9035 and 0.4094 respectively. This indicates that number of branches to have contributed much higher to grain yield among the growth characters tested. This is expected because of the proportionality of number of branches to number of leaves which will translate to increased yield. The combined contributions of plant height and leaf area index were negative.

Table 3: Direct and Combined Contributions (\%) and Residual Effects of some Growth Characters to Grain Yield of Soybean in 2014 wet season.

\section{Character}

Percentage Contribution

\begin{tabular}{lc} 
Direct contributions & $\left(\mathbf{P}_{\mathbf{1}}\right)^{\mathbf{2}} \times \mathbf{1 0 0}$ \\
\hline Plant height & $\left(\mathrm{P}_{1}\right)^{2}$ \\
Number of leaves & $\left(\mathrm{P}_{2}\right)^{2}$ \\
Number of branches & $\left(\mathrm{P}_{3}\right)^{2}$ \\
Leaf area index & $\left(\mathrm{P}_{4}\right)^{2}$ \\
Plant dry matter & $\left(\mathrm{P}_{5}\right)^{2}$
\end{tabular}

\subsection{4}

3.8563

31.0211

6.9035
Combined contributions

Plant height and Number of leaves

Plant height and Number of branches

Plant height and Leaf area index

Plant height and Plant dry matter

Number of leaves and Number of branches

Number of leaves and Leaf area index

Number of leaves and Plant dry matter

Number of branches and Leaf area index

Number of branches and Plant dry matter

Leaf area index and Plant dry matter

Residual

$1-\left(p_{1} r_{16}+p_{2} r_{26}+p_{3} r_{36}+p_{4} r_{46}+p_{5} r_{56}\right)$ $\left(2 r_{i j} p_{i} p_{j}\right) \times 100$

$\begin{array}{ll}\left(2 r_{12} p_{1} p_{2}\right) & 2.2079 \\ \left(2 r_{13} p_{1} p_{3}\right) & 6.4701 \\ \left(2 r_{14} p_{1} p_{4}\right) & -2.6906 \\ \left(2 r_{15} p_{1} p_{5}\right) & -0.1239 \\ \left(2 r_{23} p_{2} p_{3}\right) & 13.6061 \\ \left(2 r_{24} p_{2} p_{4}\right) & -4.1999 \\ \left(2 r_{25} p_{2} p_{5}\right) & -0.0427 \\ \left(2 r_{34} p_{3} p_{4}\right) & -8.8682 \\ \left(2 r_{35} p_{3} p_{5}\right) & -0.3991 \\ \left(2 r_{45} p_{4} p_{5}\right) & -0.3228 \\ \left.p_{5} r_{56}\right) & 50.1669 \\ & 100.0000\end{array}$

(-2.6906). Similar trend was observed for the combined effects of plant height and plant dry matter, number of leaves and leaf area index, number of leaves and plant dry matter, number of branches and leaf area index, number of branches and plant dry matter, as well as leaf area index and plant dry matter in which $-0.1239,-4.1999,-0.0427,-8.8682,-0.3991$ and -0.3228 were contributed respectively. There were slight increase and positive combined contributions of plant height and number of leaves, plant height and number of branches as well as number of leaves and number of branches in which 2.2079, 6.4701 and 13.6061 were contributed respectively. Out of all these contributions, $50.1669 \%$ could now be accounted for as residuals (Figure 1 ). This might be due to variation in the rates of applied fertilizer as reported by Majid et al. (2009) on the effect of Rhizobium inoculation, N and $\mathrm{P}$ fertilization on growth, yield and nodulation of Soybean.

\section{CONCLUSION}

The results of the simple correlation analysis revealed a highly significant and positive association between and amongst most of the characters assessed. Similarly, path coefficient analysis between growth and yield components revealed that number of branches per plant had the greatest effect on the grain yield of soybean. The combined contributions were also greatest via number of leaves and number of branches. Advanced study is therefore suggested to validate these results for selection of desirable character for increased yield of Soybean in the study area. 


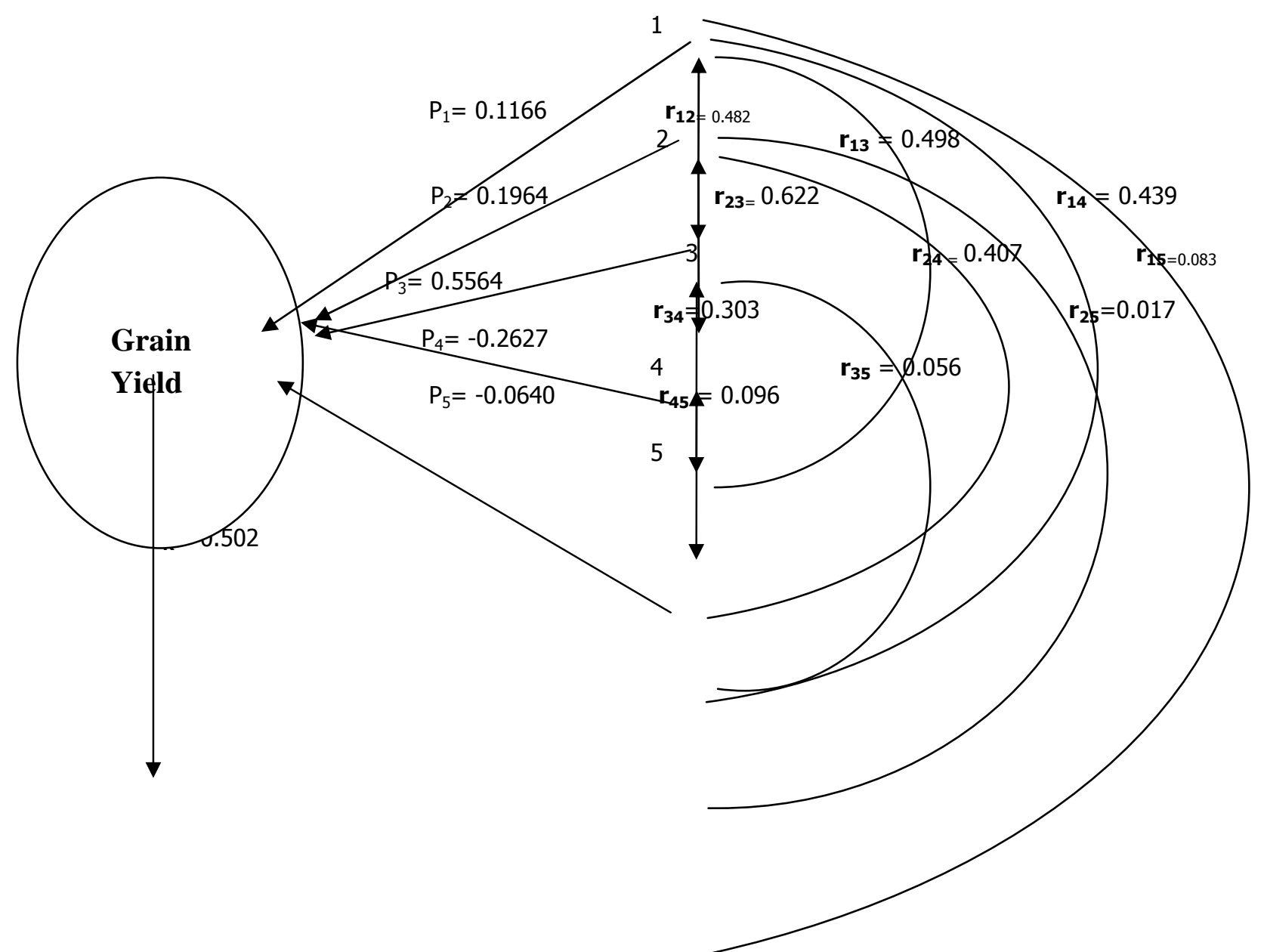

Figure 1: Path diagram showing association of some growth characters to grain yield of Soybean during 2014 wet season at Minjibir and BUK

$$
\begin{aligned}
& 1=\text { Plant Height } \\
& 2=\text { Number of Leaves } \\
& 3=\text { Number of Branches } \\
& 4=\text { Leaf Area Index } \\
& 5=\text { Plant Dry Matter }
\end{aligned}
$$

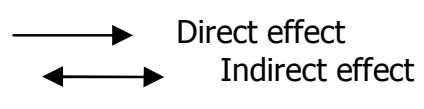

\section{REFERENCES}

Adeniji, O. T. and Peter, J. M. (2005). Stepwise regression analysis of pod and seed yield characters in segregating F2 population of West African Okra (Abelmoschus caillei.) Proceedings of $30^{\text {th }}$ Conference, Genetic Society of Nigeria, pp250-258.

Gomez, K. A and Gomez, A. A. (1984). Statistical Procedures for Agricultural Research,

$2^{\text {nd }}$ edition. John Wiley and Sons Inc., New York.

IITA (1993). Archival Report (1988-1992), Crop Improvement Division, Grain Legume Improvement Program Part III. Soybean Biological Nitrogen Fixation. Pp: 10.

Khan, A., M. Hatam and A. Khan (2000). Heritability and interrelationship among yield determining components of soybean varieties. Pakistan
Journal of Agricultural Research, 116: 5-8.

Majid, M. T., M. K. Abbasi., R. Nasir., K. Abdul and H. K. Mushtaq (2009). Effect of Rhizobium Inoculation and NP fertilization on growth, yield and nodulation of Soybean (Glycine max L.) in the sub-humid hilly region of Rawalakot Azad Jammu and Kashmir, Pakistan. African Journal of Biotechnology 8(22): $6191-6200$.

Poohlman, J. M. (1959). Breeding Sugarbeets. Breeding Field Crops. Holt Rinehart and Winston Inc., New York pp. 329 - 352

Shahid I, Tariq, M., Tahira, M. A., Muhammad, A., and Muhammad, S. (2003). Path coefficient analysis in different genotypes of soybean (Glycine max (L.) Merill). Pakistan Journal of Biological Science 6(12): 1085 - 1087. 
Singh, J. and H.S. Yadava (2000). Factors determining seed yield in early generation of Soybean. Crop Research Hisar 20: 239-243.

Singh, K., S. Singh and D. S. Kier (2000). Correlation and regression studies among various growth and yield parameters of Soybean (Glycine max L. Merill) under Punjab conditions. Crop Res Hisar 19: 287 - 297.

Simmond, N. W., J. Smartt, S. Millen, and W. Spoor (1999). Principles of crop

improvement, $2^{\text {nd }}$ edition, Published Longman
Group Ltd. Pp 252-256.

Sreenivas, G., Arya, K., Sheeba, R. I. And Jessy, M. K. (2015). Character association and path analysis for yield and yield components in Okra (Abelmoschus esculentus (L.) Moench). International Journal of Scientific Research 4(6): 141- 143.

Shrivastava, M. K., R. S. Shukla and P. K. Jain (2001). Path coefficient analysis in diverse genotype of soybean (Glycine max (L.) Merr.). Advances in Plant Sciences, 4: 47-51. 